\title{
Antisépticos orales, ¿los estamos utilizando de manera correcta?
}

\author{
Saray Aranda Romo, Juan Manuel Mendoza Méndez, Juan \\ Antonio Cepeda Bravo y Othoniel Hugo Aragón Martínez
}

\begin{abstract}
Resumen
Los enjuagues bucales son soluciones que se emplean después del cepillado para eliminar las bacterias que causan la caries, la inflamación de las encías y el mal aliento, con la finalidad de mantener la boca limpia y sana. Sin embargo, en ocasiones, la falta de conocimiento del consumidor deriva en el abuso en su empleo, lo que provoca una serie de efectos adversos que deben ser conocidos por los usuarios. Los medios de comunicación juegan un papel muy importante para que la población utilice los enjuagues bucales y los odontólogos, en algunos casos, los recetan a sus pacientes, junto con el cepillado dental, para el tratamiento de enfermedades. El objetivo del artículo es mostrar a la población los tipos de enjuagues bucales que existen en el mercado, cómo funcionan, y sus ventajas y desventajas, con la finalidad de evitar su uso indiscriminado. Además, se discute sobre el empleo de bacterias "buenas" como auxiliares en la higiene bucal. Esta nueva terapia ha demostrado ser segura y eficaz por lo que probablemente en poco tiempo estará disponible en el mercado.
\end{abstract}

Palabras clave: enjuague bucal, antiséptico oral, caries, periodontal, halitosis.

\section{MOUTHRINSES, ARE WE USING THEM CORRECTLY?}

\begin{abstract}
Oral mouth rinses are solutions that are used after brushing to eliminate the bacteria that cause tooth decay, gingivitis and bad breath, in order to keep the mouth clean and healthy. However sometimes, the lack of knowledge of the consumer results in abuse in their employment, generating a series of adverse effects that must be known by users. Media is important in promoting the use of mouthwashes in the population and dental care professionals in some cases prescribe them as auxiliary teeth brushing. The aim of this article is to show the types of oral mouth rinses that exist in the market, how they work and their advantages and disadvantages, in order to avoid its indiscriminate use. In addition, the employment of good bacteria as an aid in oral hygiene is discussed. This new therapy has been shown to be safe and effective, therefore, it will probably be available in the market in a short time.
\end{abstract}

Keywords: mouthwash, oral antiseptic, caries, periodontal, halitosis.

Dol: http://doi.org/10.22201/codeic.16076079e.2020.v21n2.a6 


\section{Saray Aranda Romo}

Egresada de la Facultad de Estomatología de la UASLP, con especialidad en patología bucal y medicina bucal. Cuenta con maestría y doctorado en Ciencias Biomédicas Básicas. Es miembro del Sistema Nacional de Investigadores (SNI), profesora investigadora de tiempo completo y coordinadora de la Clínica de diagnóstico de la Facultad de Estomatología de la UASLP.

\section{Juan Manuel Mendoza Méndez}

manueluaslp5@gmail.com

Egresado de la Facultad de Enfermería de la Universidad Autónoma de San Luis Potosí (UASLP). Actualmente, cursa la maestría en Ciencias Biomédicas Básicas, de la Facultad de Medicina de la UASL, y lleva a cabo investigación en microbiología molecular oral, en la Facultad de Estomatología de dicha universidad.

\section{Juan Antonio Cepeda Bravo}

ja cepeda@yahoo.com

Maestro en ciencias odontológicas con especialidad en periodoncia. Profesor investigador de tiempo completo de la Facultad de Estomatología de la UASL y coordinador de la especialidad de periodoncia de la Facultad de Estomatología, UASLP.

\section{Othoniel Hugo Aragón Martínez}

ohugoam@yahoo.com.mx

Químico Farmacobiólogo, cuenta con Maestría y Doctorado en Ciencias Biomédicas Básicas. Está a cargo del Departamento de Farmacología de la Facultad de Medicina de la UASLP. Actualmente, forma parte del snı, en el nivel ı. Profesor asociado en el Posgrado en Ciencias Biomédicas Básicas de la Facultad de Medicina, UASLP. 


\section{Salud y enfermedad buco-dental}

El cepillado de dientes es esencial para mantener una boca sana, ya que permite la eliminación de restos de comida que se quedan adheridos a los dientes, los cuales rápidamente son utilizados por las bacterias para producir sustancias que causan enfermedades en los dientes (caries), encías (gingivitis) o en el hueso que soporta los dientes (periodontitis) (Krzyściak \& Skalniak, 2014). Así pues, el cepillado favorece que crezcan en la boca bacterias benéficas que mantienen a los dientes fuertes y sanos.

Sin embargo, cuando quedan restos de alimentos que contienen azúcar en los dientes, éstos sirven de comida para las bacterias dañinas (Streptococcus mutans), que empiezan a crecer de manera descontrolada y a sobrepasar a las bacterias benéficas (Streptococcus dentisani). Lo anterior ocasiona que el diente se debilite y haya desmineralización o caries dental (Esberg et al., 2017). Por otro lado, esos restos de comida pueden quedar atrapados entre la encía y el diente, $y$, entonces, las bacterias de la boca comienzan a formar una estructura muy delgada llamada biopelícula, la cual está constituida por una gran cantidad de microorganismos que son capaces de activar a las células de defensa para evitar que se extiendan. Así, la encía se pone roja, hinchada y sangrante, lo cual llamamos gingivitis (ver imagen 1). Si la biopelícula logra meterse al hueso que soporta a los dientes, comienza a destruirlo, y a mover las piezas dentales (periodontitis) (Colombo \& Tanner, 2019). Todo este desequilibrio, en donde predominan las bacterias dañinas, favorece la síntesis de compuestos llamados "ácidos grasos y compuestos volátiles de sulfuro", ambos responsables del mal aliento (Scully, 2014).

Figura 1. a) Etiología de la caries. Las bacterias acidófilas (como Streptococcus mutans) se alimentan de los azúcares presentes en el medio oral y producen ácido acético y ácido

láctico. Altas concentraciones de esos ácidos favorecen la desmineralización, debilitando las piezas dentarias $y$ provocando fracturas. b) La enfermedad periodontal se da dentro del espacio subgingival, donde la acumulación de microorganismos (como P. gingivalis) provoca una inflamación, que favorece la difusión de nutrientes usados por esta bacteria misma para su crecimiento.

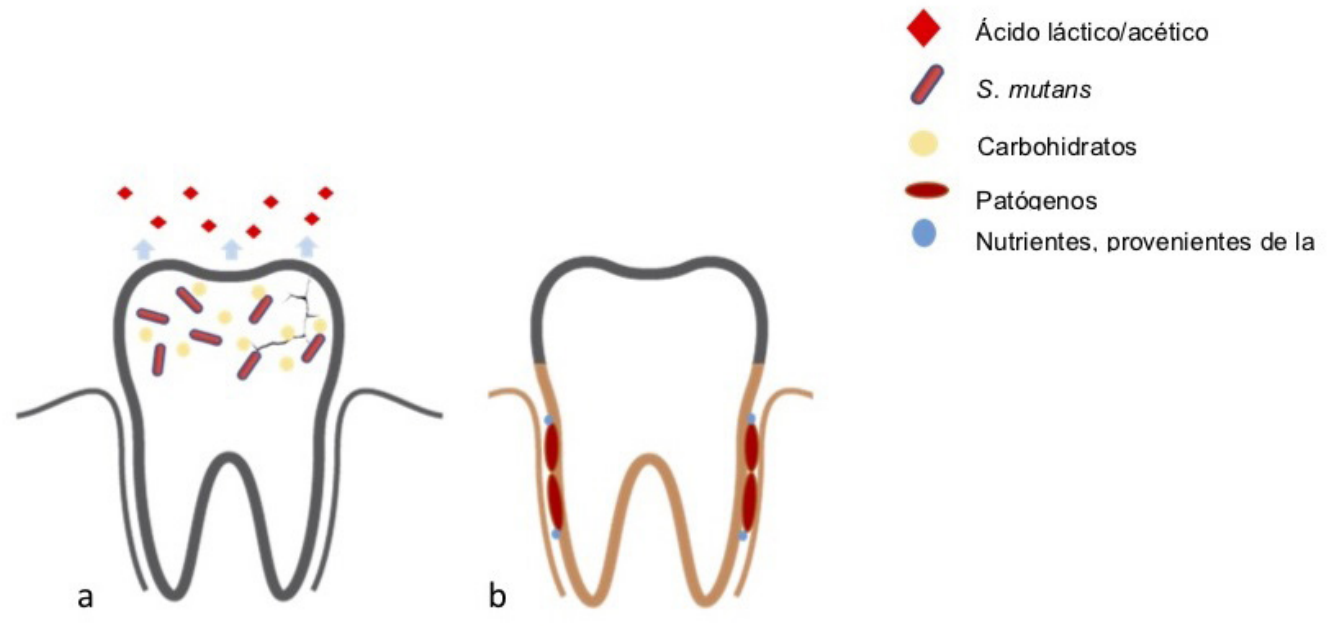




\section{Higiene bucal}

Con la finalidad de mantener a las bacterias en equilibrio, la función principal del odontólogo es educar al paciente mediante la implementación de estrategias como la enseñanza de una correcta técnica de cepillado, el uso de hilo dental, o modificaciones a la dieta, así como la prescripción de enjuagues bucales (Osso \& Kanani, 2013). Éstos últimos son soluciones que se emplean antes o después del cepillado dental para reducir temporalmente las bacterias que producen el mal aliento, la caries y la inflamación de las encías, dejando un aliento fresco y un sabor agradable (Yang et al., 2015).

Existen dos tipos de enjuagues bucales: los cosméticos y los terapéuticos. Los primeros pueden controlar el mal aliento y dejar un agradable sabor. En contraste, los segundos poseen ingredientes activos que ayudan a controlar o reducir enfermedades bucales mediante la adición de flúor para prevenir el desarrollo de caries o antisépticos para prevenir gingivitis y periodontitis (Silverman \& Wilder, 2006).

Tabla 1. Enjuagues bucales más comunes en México (Laboratorio PROFECO, 2009).
La eficacia de los enjuagues bucales terapéuticos depende de la composición del antiséptico. Su presentación comercial, mecanismo de acción, ventajas e indicaciones se muestran en la tabla 1.

*De acuerdo con la dosis administrada y uso prolongado.

\begin{tabular}{|c|c|c|c|c|}
\hline $\begin{array}{l}\text { Principio } \\
\text { activo }\end{array}$ & $\begin{array}{l}\text { Cloruro de } \\
\text { cetilpiridinio }\end{array}$ & Aceites esenciales & Flúor & Clorhexidina \\
\hline Productos & Scope $®$ & Listerine $\AA$ & Dental max $®$ & Oral-B gingivitis $®$ \\
\hline Alcohol & $\mathrm{SI}$ & $\mathrm{SI}$ & $\mathrm{NO}$ & $\mathrm{NO}$ \\
\hline $\begin{array}{c}\text { Mecanismo de } \\
\text { acción }\end{array}$ & $\begin{array}{l}\text { Actúa sobre la pared } \\
\text { de bacterias y hongos }\end{array}$ & $\begin{array}{c}\text { Actúa sobre la } \\
\text { pared de bacterias y } \\
\text { hongos }\end{array}$ & $\begin{array}{c}\text { Favorece el } \\
\text { endurecimiento del } \\
\text { esmalte dental }\end{array}$ & $\begin{array}{c}\text { Actúa sobre la pared } \\
\text { de bacterias, virus y } \\
\text { hongos }\end{array}$ \\
\hline Uso sugerido & $\begin{array}{l}\text { Dos veces al día por } \\
30 \text { s } 2 / 30 z \text { y escupir }\end{array}$ & $\begin{array}{l}\text { Dos veces al día por } \\
30 \text { s } 2 / 30 z \text { y escupir }\end{array}$ & $\begin{array}{l}\text { Dos veces al día por } \\
30 \text { s } 2 / 30 z \text { y escupir }\end{array}$ & $\begin{array}{c}\text { Después del cepillado } \\
\text { diluir } 1 / 2 \text { oz con agua y } \\
\text { enjuagar, escupir }\end{array}$ \\
\hline Beneficios & $\begin{array}{c}\text { Reduce la placa } \\
\text { Controla y previene la } \\
\text { gingivitis } \\
\text { Reduce el mal aliento } \\
\text { hasta por } 12 \mathrm{hrs}\end{array}$ & \begin{tabular}{|c|} 
Reduce la placa \\
Fortalece los dientes \\
Previene la gingivitis
\end{tabular} & $\begin{array}{c}\text { Protege contra la } \\
\text { caries }\end{array}$ & $\begin{array}{c}\text { Validado por la FDA\& } \\
\text { para el tratamiento } \\
\text { de la gingivitis }\end{array}$ \\
\hline $\begin{array}{l}\text { Efectos } \\
\text { adversos }\end{array}$ & $\begin{array}{c}\text { Pigmentación café en } \\
\text { los dientes, ulceras } \\
\text { orales e irritación de } \\
\text { la boca }\end{array}$ & $\begin{array}{l}\text { Ardor, quemadura, } \\
\text { alergia, dolor de la } \\
\text { encía, lengua negra } \\
\text { vellosa, candidiasis }\end{array}$ & $\begin{array}{c}\text { Afección esquelética, } \\
\text { renal, neurológica, } \\
\text { hormonal* }\end{array}$ & $\begin{array}{l}\text { Pigmentación dental, } \\
\text { incremento en la } \\
\text { formación de sarro, } \\
\text { alteración del sentido } \\
\text { del gusto }\end{array}$ \\
\hline
\end{tabular}


Los enjuagues bucales se venden sin receta y son de fácil acceso para la población, se pueden adquirir en supermercados y farmacias, generalmente. Los precios varían entre $\$ 48$ y $\$ 300$ pesos. Los medios de comunicación son los encargados de recomendar su uso rutinario como coadyuvantes en el cuidado de la salud oral. El consumidor es atraído por los beneficios publicitados por el vendedor: dientes fuertes, aliento fresco, blanqueamiento saludable, entre otros. Esto lleva a una rutina de consumo fuera de los criterios terapéuticos odontológicos adecuados y a su uso indiscriminado (Tanner et al., 2011).

Sólo existen datos con respecto a la utilización de enjuagues bucales en Estados Unidos. En el año 2011, 188.16 millones de habitantes consumían enjuagues bucales. Para el año 2018, la cifra aumentó a 202.04 millones. Se prevé que para el 2020, suba a 205.59 millones de consumidores (Lemos \& Villoria, 2008). Desafortunadamente, se desconoce el porcentaje de cuántos de éstos son usados con prescripción médica y cuántos no.

El abuso en el consumo de enjuagues bucales representa un riesgo para la salud oral y sistémica de los individuos. Por ejemplo, muchos enjuagues bucales contienen alcohol y deshidratan la mucosa bucal, lo que afecta el flujo salival, y si éste disminuye el riesgo a desarrollar caries se incrementa (Lemos \& Villoria, 2008). Por otro lado, el uso de enjuagues que contienen alcohol se ha asociado con el desarrollo de cáncer oral y orofaríngeo, en diversos estudios. Esto se debe a que la exposición constante al alcohol favorece la absorción de compuestos cancerígenos como tabaco, metales y algunos aditivos del enjuague bucal como el uretano (Ustrell-Borràs, Traboulsi-Garet, \& Gay-Escoda, 2019). El uso de aceites esenciales y del cetilpiridinio también puede tener un impacto negativo en las restauraciones dentales, lo que favorece su fractura, fenómeno frecuente en sujetos que hacen uso excesivo de los enjuagues bucales (Silverman \& Wilder, 2006).

Si bien los enjuagues bucales eliminan un gran porcentaje de los microorganismos responsables de enfermedades, el consumidor debe saber que también tienen efectos adversos sobre la estabilidad de las bacterias benéficas que habitan en la boca (ver figura 2). Al igual que con el consumo de antibióticos sin prescripción médica, los enjuagues eliminan las bacterias benéficas o probióticas del individuo. Entre ellas destacan las que ayudan al control de la presión arterial, por lo que ésta podría incrementar con el uso de enjuagues que contienen clorhexidina al 0.12\% (Senkus \& Crowe-White, 2019). Esto se debe a que las bacterias de la boca producen una sustancia (óxido nitrico), que permite que los vasos sanguíneos se dilaten manteniendo la presión arterial dentro de los rangos normales. 
Figura 2. a) Se muestra una microbiota colonizada por microorganismos relacionados con la salud y la enfermedad.

b) Tras un tratamiento con enjuague bucal terapéutico, se evidencia cómo no sólo las cepas responsables de la enfermedad son erradicadas, sino también aquellas responsables de la salud bucal.

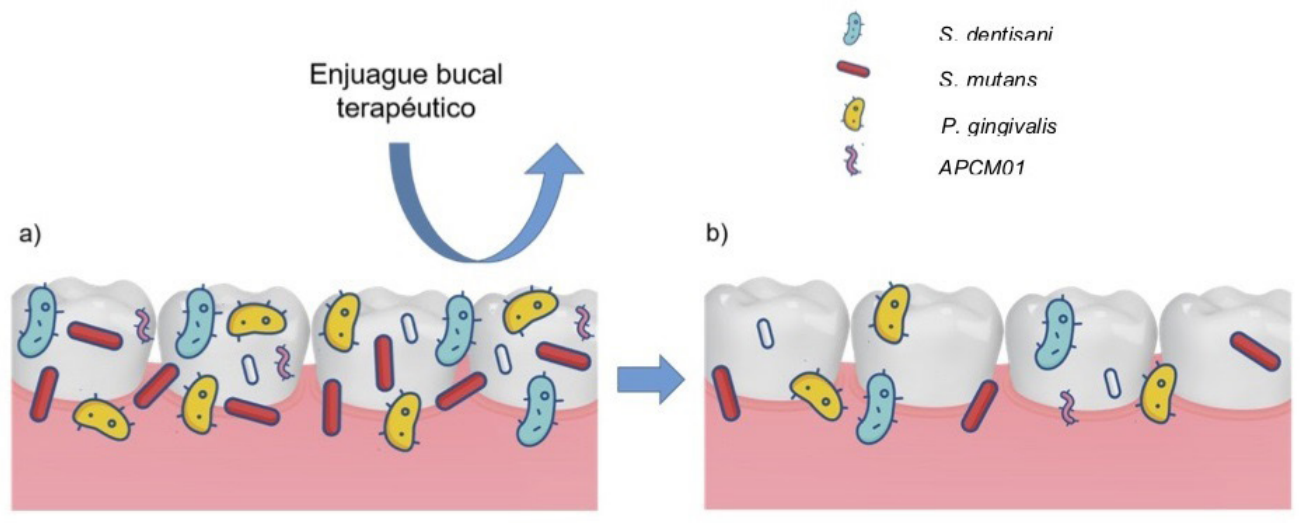

Otra bacteria probiótica importante que es eliminada por el uso de enjuagues bucales, es el Streptococcus dentisani, descubierta en 2014, por un grupo de investigadores en Valencia, España (Camelo-Castillo, et al., 2014). Posteriormente, en 2017, se demostró que dicha bacteria era capaz de inhibir el crecimiento de Streptococcus mutans, la principal causante de caries dental, así como a las bacterias responsables de la enfermedad periodontal y mal aliento (LópezLópez, et al., 2017). Pese a que no se cuentan con estudios sobre la viabilidad de $S$. dentisani frente a soluciones antisépticas, sus características microbianas hacen pensar que también son susceptibles a la clorhexidina y al cloruro de cetilperidinio.

El cepillado dental y la utilización de enjuagues bucales de manera rutinaria no ha podido reducir la frecuencia de enfermedades bucales a pesar de que llevan en el mercado más de 100 años (Garry \& Boran, 2017). No obstante, el uso médico prolongado de antisépticos orales a base de clorhexidina tampoco parece ser la solución para evitar el mal aliento. Schmidt et al. (2016) demostraron que el uso de ésta provocaba un daño severo a las paredes que recubren la boca, lo que ocasiona la muerte de las células que la forman. De esta manera, la boca se vuelve más susceptible a ulceraciones o lesiones que generen sangrado.

Es necesario, entonces, buscar terapias alternativas al cepillado dental y uso de enjuagues bucales, con la finalidad de controlar el crecimiento de las bacterias dañinas y favorecer la proliferación de aquellas con potencial benéfico para el individuo. Por tal motivo la bacterioterapia se ha introducido recientemente con resultados prometedores (Alok et al., 2017). Este procedimiento se basa en la administración de un gel que contiene altas concentraciones de la bacteria probiótica (S. dentisani), la cual, de acuerdo a un estudio reciente, logra adherirse a la superficie dental. Este probiótico oral (AB-Dentisanium®) solo se encuentra disponible en España, pero se espera que pronto se encuentre en México (Ferrer et al., 2019). 
Figura 3. a) Se puede observar la proporción entre las especies S. dentisani y S. mutans, con bajas concentraciones de arginina, en el medio oral. b) Tras un tratamiento con agentes externos compuestos por arginina, las copias de S. mutans disminuyen gracias al aumento de $S$. dentisani, a su actividad bactericida y un aumento gradual del pH, en el medio oral.
La investigaciónactual se dirigeal descubrimiento de nuevas bacterias probióticas orales, las cuales puedan ser usadas como alternativas para mantener la salud oral de los individuos y a que no se desarrollen enfermedades una vez que se incorporen a la boca. También se investigan virus que puedan infectar selectivamente a una bacteria (bacteriófagos). Se ha evaluado al bacteriófago ApCM01, que ha demostrado infectar selectivamente a S. mutans y eliminarlo (Dalmasso et al., 2015).

Asimismo, se encuentran en investigación enjuagues bucales con arginina, sustancia que es considerada un prebiótico o alimento de las bacterias benéficas, quienes la convierten en amoniaco, capaz de eliminar la producción de ácidos y de esta forma evitar la caries dental (Geraldeli et al., 2017, ver figura 3).

\section{Tratamiento con arginina}
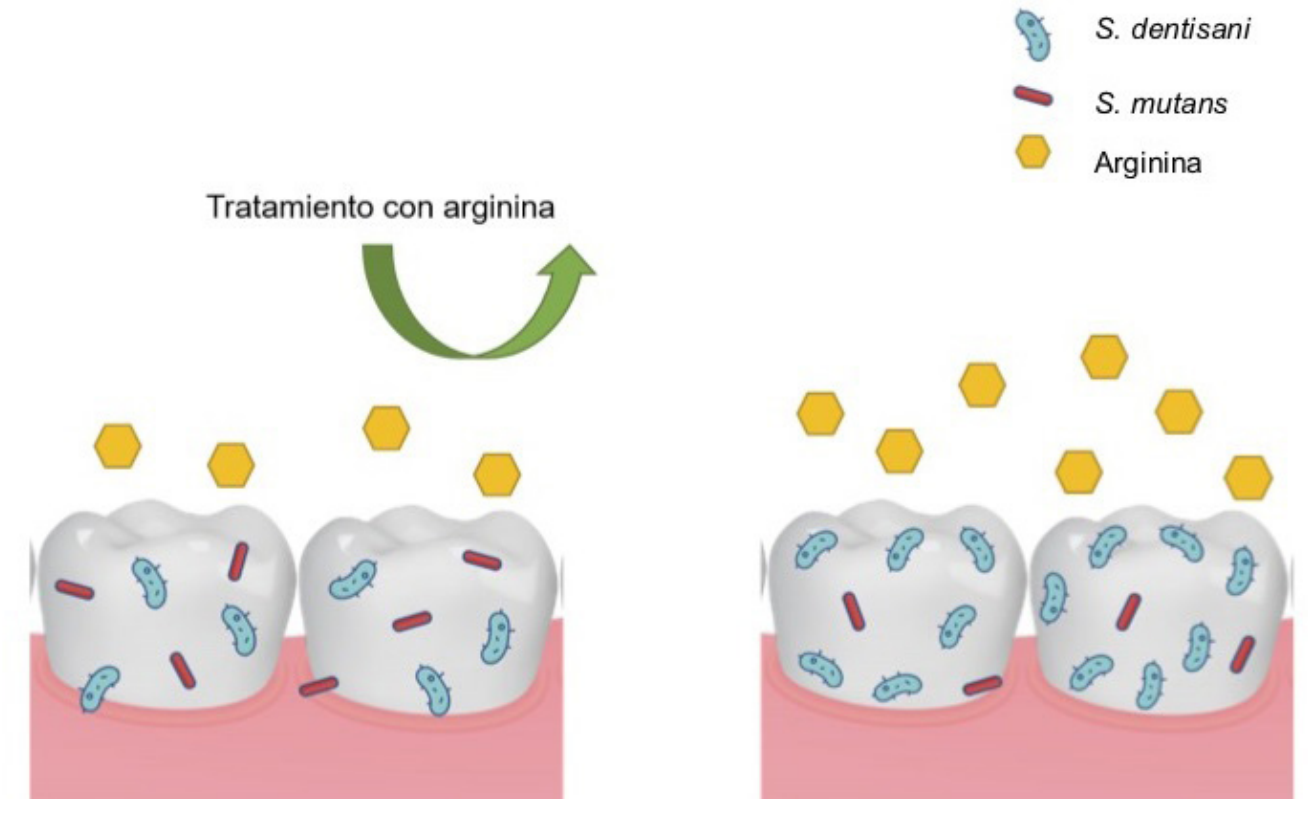

\section{Conclusiones}

Actualmente existe un uso indiscriminado de los enjuagues bucales, situación que se debe a que los pacientes los adquieren sin la orientación apropiada por un profesional. Es necesario limitar su empleo en el tratamiento de enfermedades bucales, bajo estricta indicación y supervisión por parte del odontólogo, el cual recetará el enjuague bucal adecuado, al hacer un análisis de las características de cada paciente.

\section{Referencias}

Alok, A., Singh, I. D., Singh, S., Kishore, M., Jha, P. C., \& lqubal, M. A. (2017). Probiotics: A New Era of Biotherapy. Advanced Biomedical Research, 6, 1-31. Dol: https://doi. org/10.4103/2277-9175.192625. 
"Antisépticos orales, ¿los estamos utilizando de manera correcta?" Juan M. Mendoza Méndez, Saray A. Romo,

Juan A. Cepeda Bravo y Othoniel H. Aragón Martínez

Vol. 21, Núm. 2, marzo-abril 2020

Revista Digital Universitaria

* Camelo-Castillo, A., Benitez-Paez, A., Belda-Ferre, P., Cabrera-Rubio, R., \& Mira, A. (2014). Streptococcus dentisani sp. Nov., a novel member of the mitis group. International journal of systematic and evolutionary microbiology, 64, 60-65. Dol: https://doi.org/10.1099/ijs.0.054098-0.

* Colombo, A. P. V., \& Tanner, A. C. R. (2019). The Role of Bacterial Biofilms in Dental Caries and Periodontal and Peri-implant Diseases: A Historical Perspective. Journal of Dental Research, 98, 373-385. Dol: https://doi.org/10.1177/0022034519830686.

* Dalmasso, M., de Haas, E., Neve, H., Strain, R., Cousin, F. J., Stockdale, S. R., ... Hill, C. (2015). Isolation of a Novel Phage with Activity against Streptococcus mutans Biofilms. Plos One, 10,1-10. Dol: https://doi.org/10.1371/journal.pone.0138651.

* Esberg, A., Sheng, N., Mårell, L., Claesson, R., Persson, K., Borén, T., \& Strömberg, N. (2017). Streptococcus Mutans Adhesin Biotypes that Match and Predict Individual Caries Development. EBioMedicine, 24, 205-215. Dol: https://doi.org/10.1016/j. ebiom.2017.09.027.

* Ferrer, M. D., López-López, A., Nicolescu, T., Salavert, A., Méndez, I., Cuñé, J., Mira, A. (2019). A pilot study to assess oral colonization and pH buffering by the probiotic Streptococcus dentisani under different dosing regimens. Odontology, 1,112. Dol: https://doi.org/10.1007/s10266-019-00458-y.

* Garry, B., \& Boran, S. (2017). Promotion of oral health by community nurses. British Journal of Community Nursing, 22, 496-502. Dol: https://doi.org/10.12968/ bjcn.2017.22.10.496.

* Geraldeli, S., Soares, E. F., Alvarez, A. J., Farivar, T., Shields, R. C., Sinhoreti, M. A. C., \& Nascimento, M. M. (2017). A new arginine-based dental adhesive system: Formulation, mechanical and anti-caries properties. Journal of Dentistry, 63, 72-80. Dol: https://doi.org/10.1016/j.jdent.2017.05.024.

* Krzyściak, W., Jurczak, A., Kościelniak, D., Bystrowska, B., \& Skalniak, A. (2014). The virulence of Streptococcus mutans and the ability to form biofilms. European Journal of Clinical Microbiology \& Infectious Diseases: Official Publication of the European Society of Clinical Microbiology, 33,499-515. Dol: https://doi.org/10.1007/ s10096-013-1993-7.

* Laboratorio PRofeco (2009).Enjuages bucales. La promesa del aliento perfecto. Revista del consumidor, febrero, 44-51. Recuperado de: https://www.gob.mx/ cms/uploads/attachment/file/119110/Estudio Enjuagues bucales 44-51 Febrero 2009.pdf.

Lemos, C. A., \& Villoria, G. E. M. (2008). Reviewed evidence about the safety of the daily use of alcohol-based mouthrinses. Brazilian Oral Research, 22, Suppl 1, 24-31. Dol: https://doi.org/10.1590/s1806-83242008000500005.

* López-López, A., Camelo-Castillo, A., Ferrer, M. D., Simon-Soro, Á., \& Mira, A. (2017). Health-Associated Niche Inhabitants as Oral Probiotics: The Case of Streptococcus dentisani. Frontiers in Microbiology, 8,1-10. Dol: https://doi.org/10.3389/ fmicb.2017.00379. 
* Osso, D., \& Kanani, N. (2013). Antiseptic mouth rinses: An update on comparative effectiveness, risks and recommendations. Journal of Dental Hygiene, 87,10-18. Recuperado de: http://eds.a.ebscohost.com/eds/pdfviewer/ pdfviewer? vid=0\&sid=df2312db-a9a4-4cd3-a02e-2f37f0a73d63\%40sdc-vsessmgr03.

Schmidt, J., Zyba, V., Jung, K., Rinke, S., Haak, R., Mausberg, R. F., \& Ziebolz, D. (2016). Cytotoxic effects of octenidine mouth rinse on human fibroblasts and epithelial cells - an in vitro study. Drug and Chemical Toxicology, 39, 322-330. Dol: https://doi. org/10.3109/01480545.2015.1121274.

Scully, C. (2014). Halitosis. Bmı Clinical Evidence, 1, 10-16.

* Senkus, K. E., \& Crowe-White, K. M. (2019). Influence of mouth rinse use on the enterosalivary pathway and blood pressure regulation: A systematic review. Critical Reviews in Food Science and Nutrition, 8, 1-13. Dol: https://doi.org/10.1080/1 $\underline{0408398.2019 .1665495}$

* Silverman, S., \& Wilder, R. (2006). Antimicrobial mouthrinse as part of a comprehensive oral care regimen. Safety and compliance factors. Journal of the American Dental Association, 137, Suppl:22, S-26S. Dol: https://doi.org/10.14219/ jada.archive.2006.0406.

- Tanner, A. C. R., Mathney, J. M. J., Kent, R. L., Chalmers, N. I., Hughes, C. V., Loo, C. Y., Dewhirst, F. E. (2011). Cultivable Anaerobic Microbiota of Severe Early Childhood Caries. Journal of Clinical Microbiology, 49, 1464-1474. Dol: https://doi.org/10.1128/ JCM.02427-10.

* Ustrell-Borràs, M., Traboulsi-Garet, B., \& Gay-Escoda, C. (2019). Alcohol-based mouthwash as a risk factor of oral cancer: A systematic review. Medicina Oral, Patología Oral y Cirugía Bucal, 1, 1-10. Dol: https://doi.org/10.4317/medoral.23085.

* Yang, S.-J., Han, S.-H., Lee, A.-R., Jun, J.-H., Son, M.-W., Oh, S.-H., Jaehong, K. \& Paik, S.-Y. (2015). Evaluation of antimicrobial effects of commercial mouthwashes utilized in South Korea. BмB Reports, 48, 42-47. Dol: https://doi.org/10.5483/ BMBRep.2015.48.1.090.

\section{Cómo citar este artículo}

* Aranda Romo, Saray, Mendoza Méndez, Juan Manuel, Cepeda Bravo, Juan Antonio y Aragón Martínez, Othoniel Hugo (2020). Antisépticos orales, ¿los estamos utilizando de manera correcta?. Revista Digital Universitaria (RDU). Vol. 21, núm. 2 marzo-abril. Dol: http://doi.org/10.22201/codeic.16076079e.2020.v21n2.a6.

Recepción: 07/05/2019. Aprobación: 21/11/2019 